\title{
Macroparticle-enhanced cultivation of Lentzea aerocolonigenes: Variation of mechanical stress and combination with lecithin supplementation for a significantly increased rebeccamycin production
}

Kathrin Schrinner ${ }^{1}$, Marcel Schrader ${ }^{2}$, Jana Niebusch ${ }^{2}$, Kristin Althof ${ }^{2}$, Friederike Schwarzer $^{2}$, Paul-Frederik Nowka ${ }^{2}$, Anna Dinius ${ }^{2}$, Arno Kwade ${ }^{2}$, and Rainer Krull ${ }^{1}$

${ }^{1} \mathrm{TU}$ Braunschweig

${ }^{2}$ Technische Universität Braunschweig

June 12, 2021

\begin{abstract}
The actinomycete Lentzea aerocolonigenes produces the antitumor antibiotic rebeccamycin. In previous studies the rebeccamycin production was significantly increased by the addition of glass beads during cultivation in different diameters between $0.5-2 \mathrm{~mm}$ and the induced mechanical stress by the glass beads was proposed to be responsible for the increased production. Thus, this study was conducted to be a systematic investigation of different parameters for macroparticle addition, such as bead diameter, concentration and density (glass and ceramic) as well as shaking frequency, for a better understanding of the particle induced stress on L. aerocolonigenes. The induced stress for optimal rebeccamycin production can be estimated by a combination of stress energy and stress frequency. In addition, the macroparticle-enhanced cultivation of L. aerocolonigenes was combined with soy lecithin addition to further increase the rebeccamycin concentration. With $100 \mathrm{~g} \mathrm{~L}^{-1}$ glass beads in a diameter of $969 \mu \mathrm{m}$ and $5 \mathrm{~g} \mathrm{~L}^{-1}$ soy lecithin a concentration of $388 \mathrm{mg} \mathrm{L} 1$ rebeccamycin was reached after 10 days of cultivation, which corresponds to the highest rebeccamycin concentrations achieved in shake flask cultivations of L. aerocolonigenes stated in literature so far.
\end{abstract}

\section{Hosted file}

Schrinner et al - Macroparticle enhanced cultivation - Biotechnol Bioeng_2021-06-03.docx available at https://authorea.com/users/419491/articles/525975-macroparticle-enhancedcultivation-of-lentzea-aerocolonigenes-variation-of-mechanical-stress-and-combinationwith-lecithin-supplementation-for-a-significantly-increased-rebeccamycin-production 

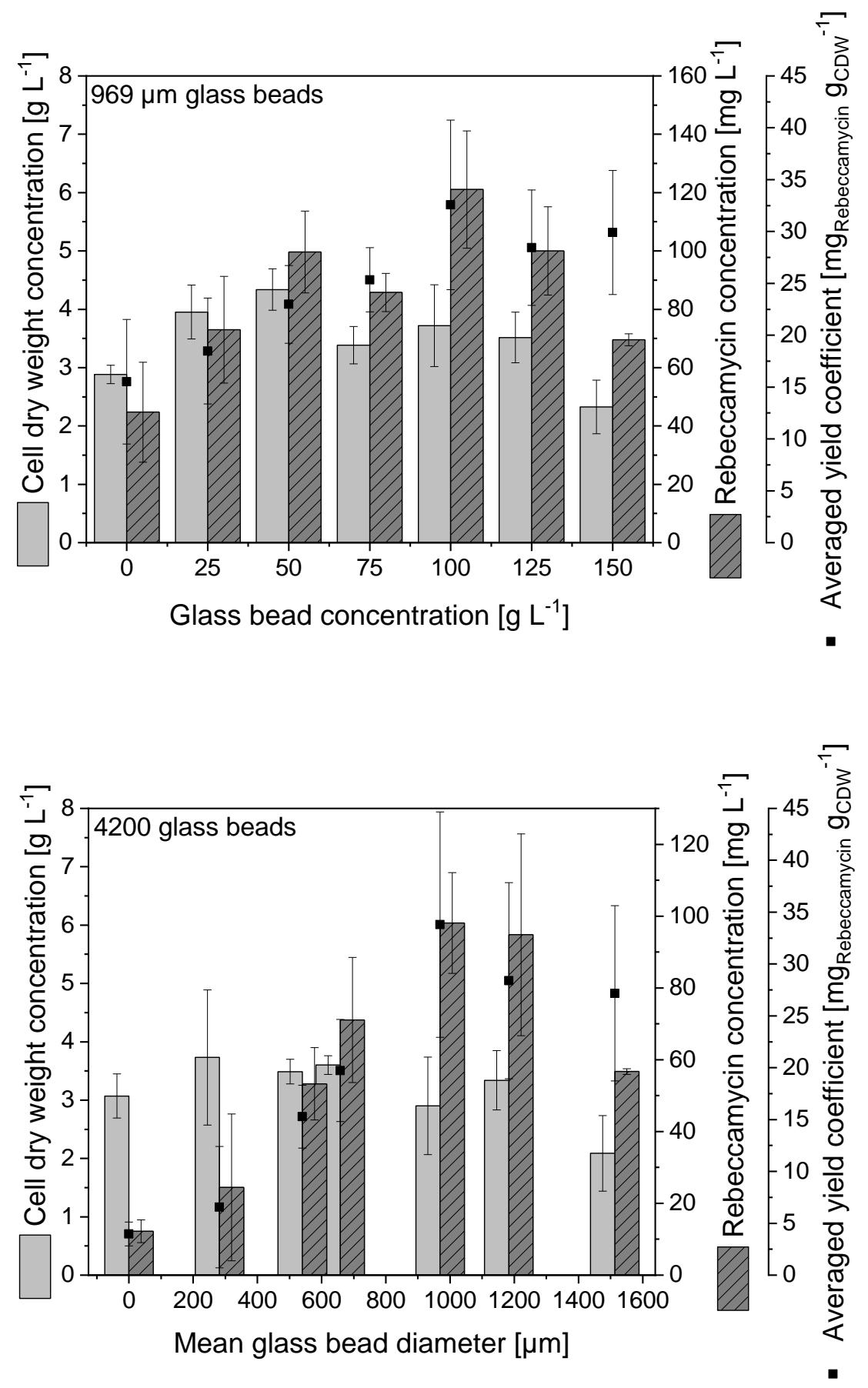


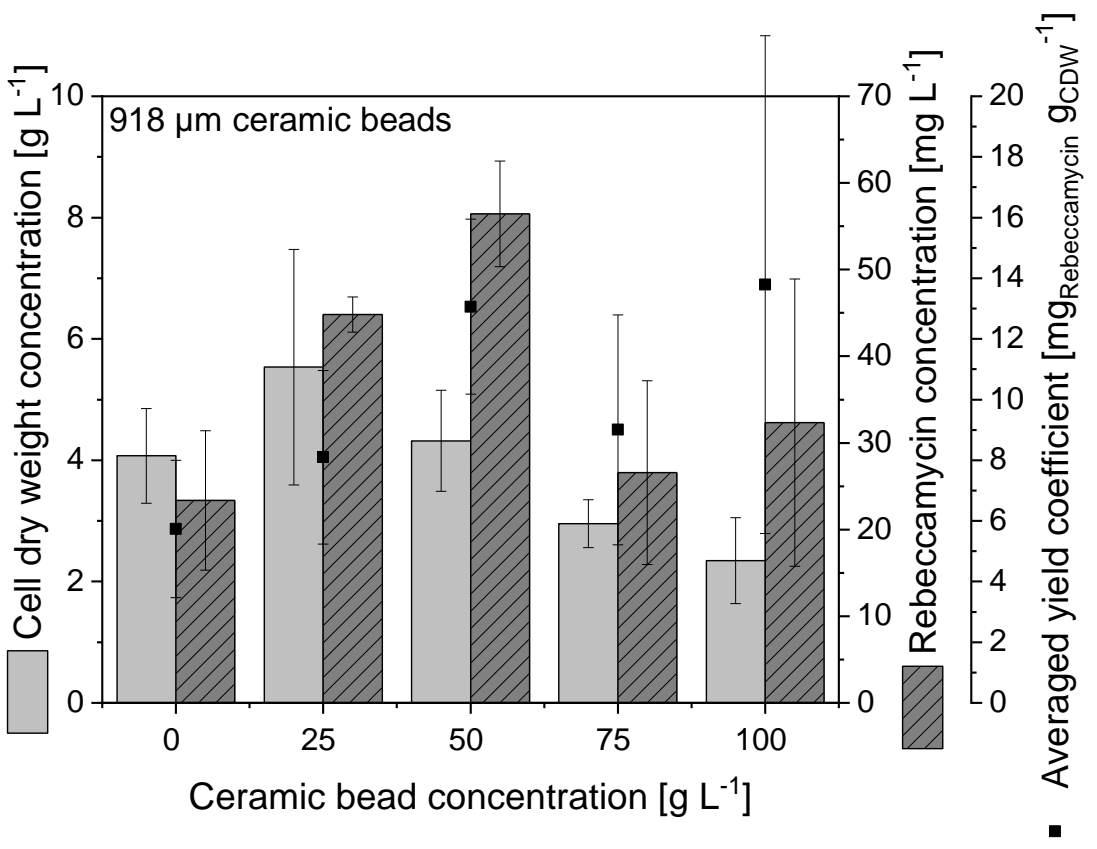



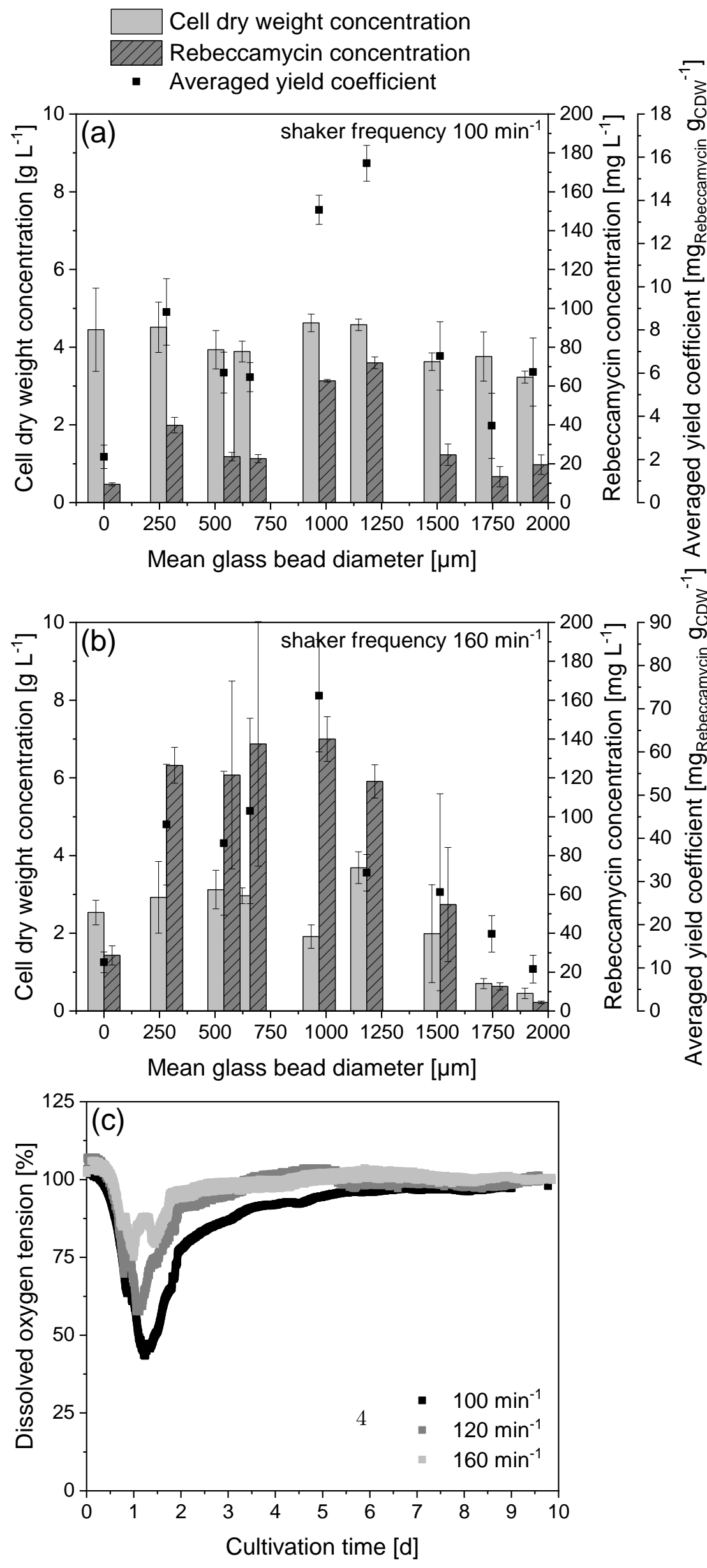


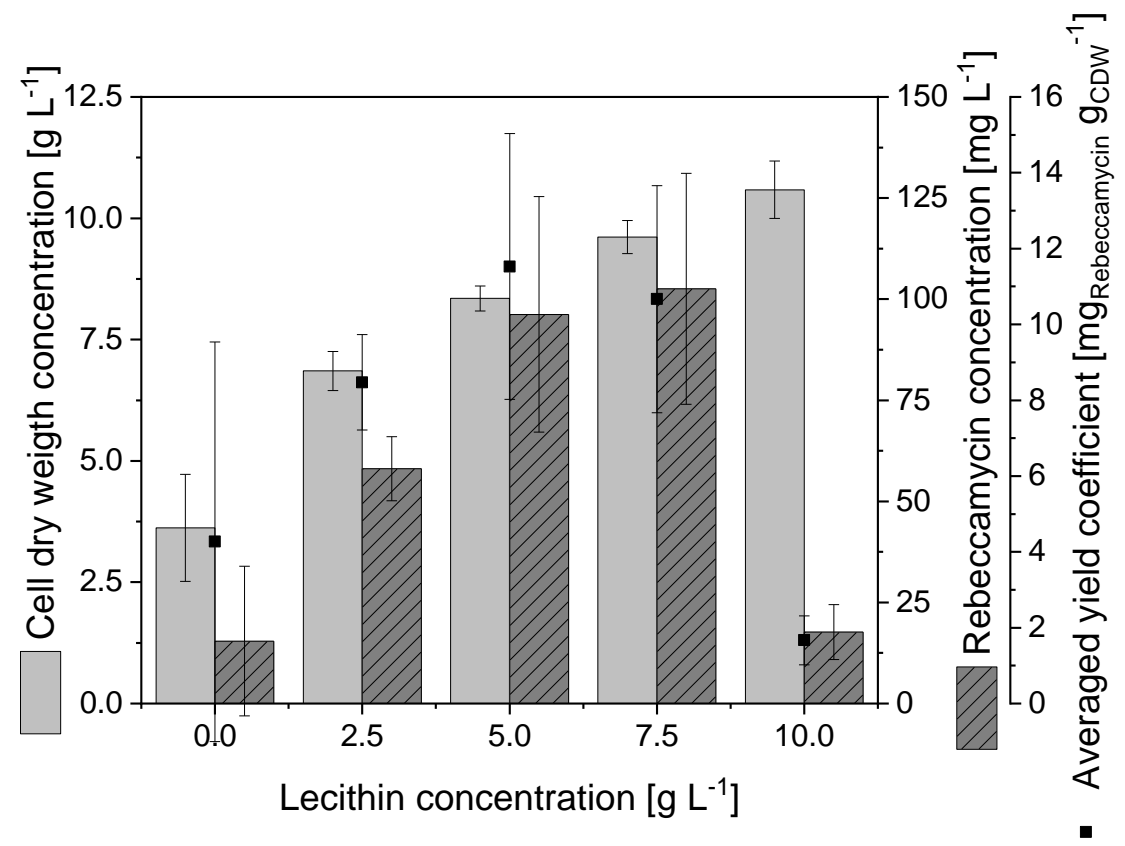



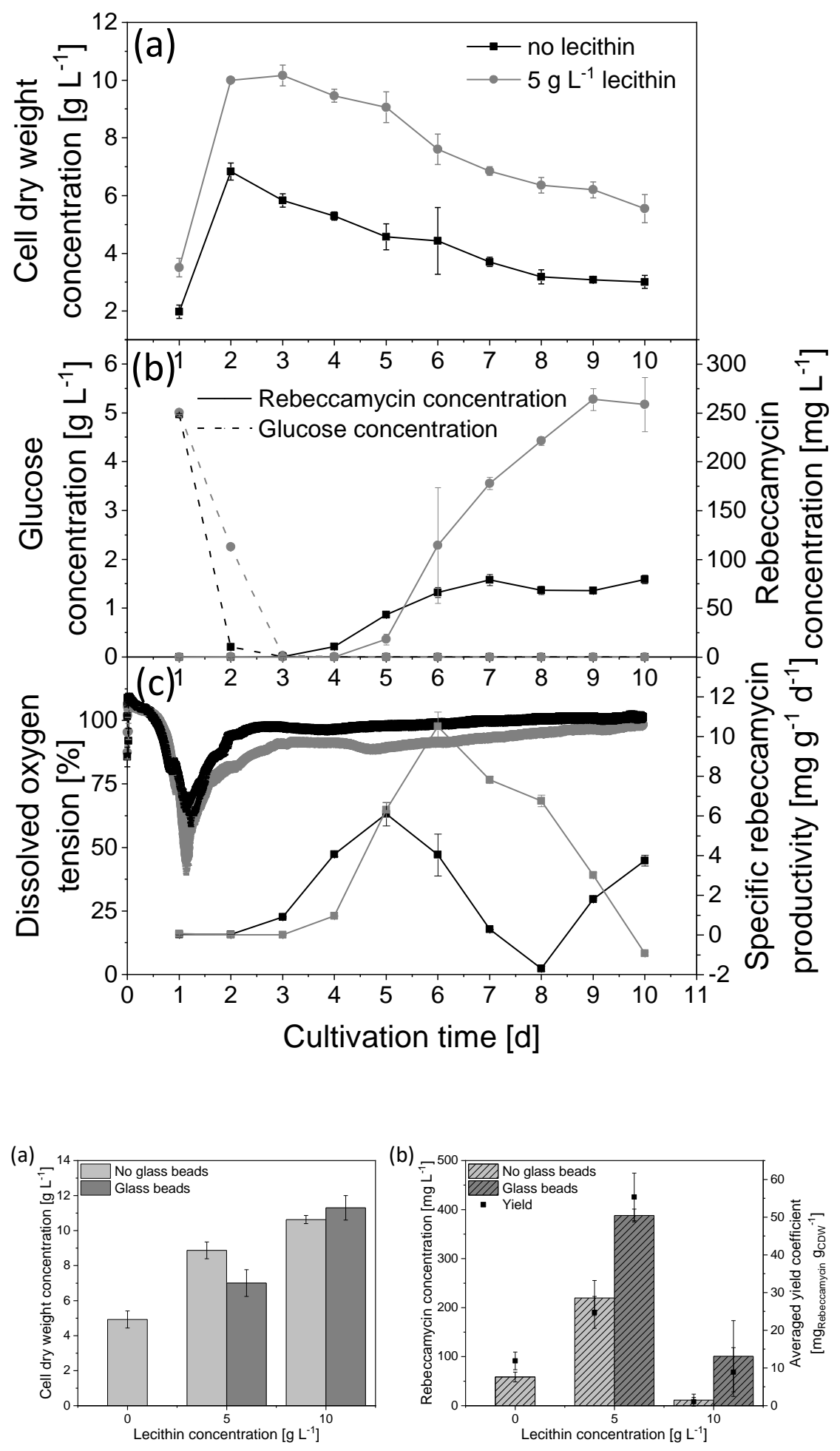


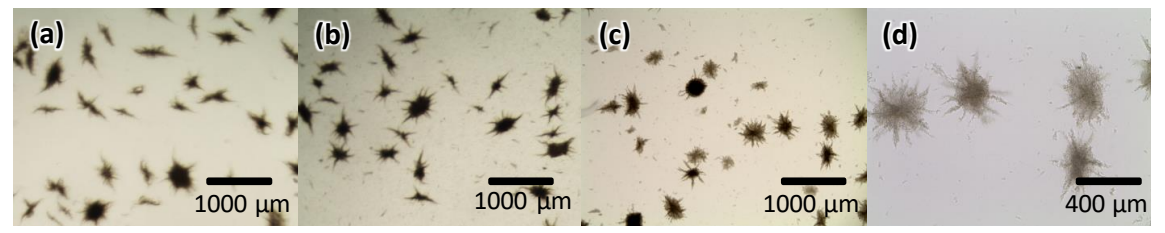

